(1)

CrossMark

\title{
Targeting fatty acid amide hydrolase as a therapeutic strategy for antitussive therapy
}

\author{
Michael A. Wortley ${ }^{1,4}$, John J. Adcock ${ }^{1,4}$, Eric D. Dubuis ${ }^{1}$, Sarah A. Maher ${ }^{1}$, \\ Sara J. Bonvini ${ }^{1}$, Isabelle Delescluse ${ }^{2}$, Ross Kinloch ${ }^{2}$, Gordon McMurray (12), \\ Christelle Perros-Huguet (10 ${ }^{2}$, Marianthi Papakosta ${ }^{2,3}$, Mark A. Birrell ${ }^{1}$ and \\ Maria G. Belvisi ${ }^{1}$
}

Affiliations: ${ }^{1}$ Respiratory Pharmacology Group, Airway Disease Division, National Heart and Lung Institute, Faculty of Medicine, Imperial College London, London, UK. ${ }^{2}$ Internal Medicine, Pfizer Global R\&D, Sandwich, UK. ${ }^{3}$ Inflammation and Immunology Research Unit, Pfizer Inc., Cambridge, MA, USA. ${ }^{4}$ Both authors contributed equally to this work.

Correspondence: Maria G. Belvisi, Respiratory Pharmacology Group, Airway Disease Division, National Heart and Lung Institute, Faculty of Medicine, Imperial College London, Exhibition Road, London, SW7 2AZ, UK. E-mail: m.belvisidimperial.ac.uk

@ERSpublications

Fatty acid amide hydrolase inhibition as a target for the development of novel, safe antitussive therapy http://ow.ly/14ZE30dbbB1

Cite this article as: Wortley MA, Adcock JJ, Dubuis ED, et al. Targeting fatty acid amide hydrolase as a therapeutic strategy for antitussive therapy. Eur Respir J 2017; 50: 1700782 [https://doi.org/10.1183/ 13993003.00782-2017].

ABSTRACT Cough is the most common reason to visit a primary care physician, yet it remains an unmet medical need. Fatty acid amide hydrolase (FAAH) is an enzyme that breaks down endocannabinoids, and inhibition of FAAH produces analgesic and anti-inflammatory effects. Cannabinoids inhibit vagal sensory nerve activation and the cough reflex, so it was hypothesised that FAAH inhibition would produce antitussive activity via elevation of endocannabinoids.

Primary vagal ganglia neurons, tissue bioassay, in vivo electrophysiology and a conscious guinea pig cough model were utilised to investigate a role for fatty acid amides in modulating sensory nerve activation in vagal afferents.

FAAH inhibition produced antitussive activity in guinea pigs with concomitant plasma elevation of the fatty acid amides $\mathrm{N}$-arachidonoylethanolamide (anandamide), palmitoylethanolamide, $\mathrm{N}$-oleoylethanolamide and linoleoylethanolamide. Palmitoylethanolamide inhibited tussive stimulus-induced activation of guinea pig airway innervating vagal ganglia neurons, depolarisation of guinea pig and human vagus, and firing of $\mathrm{C}$-fibre afferents. These effects were mediated via a cannabinoid $\mathrm{CB}_{2} / \mathrm{G}_{\mathrm{i} / \mathrm{o}}$-coupled pathway and activation of protein phosphatase $2 \mathrm{~A}$, resulting in increased calcium sensitivity of calcium-activated potassium channels.

These findings identify FAAH inhibition as a target for the development of novel, antitussive agents without the undesirable side-effects of direct cannabinoid receptor agonists.

This article has supplementary material available from erj.ersjournals.com

Received: April 132017 | Accepted after revision: June 212017

Support statement: S.A. Maher and E.D. Dubuis were funded by a project grant from the Medical Research Council (MR/K020293/1). M.A. Wortley was also funded by the North West Lung Centre Charity. The human vagus experiments in this study were undertaken with the support of the NIHR Respiratory Disease Biomedical Research Unit at the Royal Brompton \& Harefield NHS Foundation Trust and Imperial College London. Funding information for this article has been deposited with the Crossref Funder Registry.

Conflict of interest: Disclosures can be found alongside this article at erj.ersjournals.com

Copyright @ERS 2017 


\section{Introduction}

Chronic cough severe enough to interfere with the normal activities of daily life is thought to affect $\sim 7 \%$ of the population [1]. It is often associated with inflammatory airway diseases including chronic obstructive pulmonary disease, asthma, idiopathic pulmonary fibrosis, lung cancer or conditions outside the lung such as gastro-oesophageal reflux and rhinosinusitis, and is also a side-effect of drug treatments such as angiotensin-converting enzyme inhibitors [2]. Treatment-resistant cough can also be idiopathic in origin and can account for $18-42 \%$ of patients at specialist cough clinics [3]. Despite its importance, the treatment options for cough are limited and recent evidence suggests over-the-counter cough medications are ineffective [4].

The cough reflex is regulated by vagal, sensory afferent nerves which innervate the airway $[2,5]$. The cell bodies for airway sensory nerves are mostly housed in the nodose and jugular ganglia. There are several known sensory nerve subtypes present in the lung: some are more mechanically sensitive, e.g. the rapidly adapting receptors, slowly adapting receptors and the subtype known as the "cough" receptor, and some are more chemosensitive, e.g. C-fibres and A $\delta$ nociceptors. Ion channels present on these vagal nerve termini can be activated by a wide variety of stimuli to elicit cough and other reflexes. Transient receptor potential (TRP) channels are the main family of ion channels implicated in the initiation of sensory reflexes.

Previous studies have highlighted the role of cannabinoid $\mathrm{CB}_{2}$ receptors in the modulation of airway sensory nerve activity and the cough reflex $[6,7]$. However, directly administered cannabinoids are not devoid of undesirable side-effects [8]. The enzyme fatty acid amide hydrolase (FAAH) is an integral membrane protein found within the nervous system, and is responsible for the hydrolysis of the endocannabinoid $\mathrm{N}$-arachidonoylethanolamide (AEA; anandamide) and other related amidated signalling lipids, such as palmitoylethanolamide (PEA), $\mathrm{N}$-oleoylethanolamide (OEA) and linoleoylethanolamide (LEA). These signalling lipids exert their effects through various different receptors such as cannabinoid $\mathrm{CB}_{1} / \mathrm{CB}_{2}$ receptors and also via noncannabinoid receptors, including TRPV1, peroxisome proliferator-activated receptors (PPARs) and opioid receptors [9-11]. Elevating endogenous levels of AEA and other bioactive fatty acid amides (FAAs) through genetic deletion or pharmacological inhibition of FAAH elicits analgesic effects in pre-clinical models of pain and inflammation [12]. These lipid signalling molecules are synthesised and released on demand and act locally, as they are rapidly inactivated. This suggests that there may be therapeutic potential in modulating the levels of these ligands, thereby reducing the potential for side-effects that result from widespread systemic cannabinoid receptor activation.

Given $\mathrm{CB}_{2}$ receptor agonists have been shown to produce antitussive activity in pre-clinical models of cough $[6,7]$, we hypothesised that inhibition of FAAH may represent a target for the development of novel antitussive agents. In these studies we utilised the tussive agents commonly used for clinical cough challenge studies, i.e. capsaicin and citric acid (which represents a low $\mathrm{pH}$ solution) [2].

\section{Material and methods \\ Animals}

In vivo and ex vivo experiments were conducted in male Dunkin-Hartley guinea pigs (300-500 g; 400$800 \mathrm{~g}$ for single-fibre in vivo studies) (Harlan, Bicester, UK and B\&K Universal, Hull, UK) housed in a temperature-controlled $\left(21^{\circ} \mathrm{C}\right)$ room with food and water freely available for at least 1 week before commencing experimentation. The experiments were performed in accordance with the UK Home Office guidelines for animal welfare based on the Animals (Scientific Procedures) act 1986 and the ARRIVE guidelines [13].

\section{Measurement of PF-04862853 and FAA levels}

In stand-alone pharmacokinetic characterisation studies, blood samples (saphenous vein bleeds) were taken at $0,30,60120,180,240,300$ and $360 \mathrm{~min}$ after oral administration. Plasma levels of the novel FAAH inhibitor PF-04862853 were measured in plasma by liquid chromatography-mass spectrometry (LC-MS) as described previously [14, 15]. Plasma was prepared as described previously [14, 15] in separate studies to assess AEA, PEA, OEA and LEA levels, also measured by LC-MS.

\section{Conscious guinea pig cough counting}

PF-04862853 $\left(1 \mathrm{mg}^{\mathrm{kg}}{ }^{-1}\right)$ or vehicle (0.5\% methylcellulose/ $0.1 \%$ Tween 80 in saline) was administered per os $4 \mathrm{~h}$ prior to cough recording. The studies were blinded and oral dosing was performed by an independent operator. In all experiments the operator was blinded to the treatment groups. Conscious guinea pigs were placed in individual double-chamber plethysmography boxes (Buxco, Wilmington, NC, USA) and cough assessed to an aerosol of citric acid (aerosol of $0.3 \mathrm{M}$ in saline for $10 \mathrm{~min}$ ) as described previously $[7,16]$. Animals were sacrificed at the end of the experiment. 
Guinea pig and human isolated vagus nerve recording

Recording of depolarisation of isolated guinea pig and human vagus was carried out as described previously $[2,6,7,16]$. Briefly, nerves were stimulated twice with capsaicin $(1 \mu \mathrm{M})$ or low $\mathrm{pH}(\mathrm{pH})$ perfused for $2 \mathrm{~min}$ (internal control) before vehicle/FAA was perfused for $10 \mathrm{~min}$. Stimulation was then re-assessed in the presence of vehicle or FAA. After 5-10 min wash, nerves were stimulated at the end of each experiment to confirm viability. For relevant experiments, vehicle/antagonist/potassium channel blocker was perfused for $10 \mathrm{~min}$ prior to and in the presence of vehicle/FAA. For experiments to examine the role of $\mathrm{G}_{\mathrm{i} / \mathrm{o}}$ subunits, vehicle (saline) or pertussis toxin (PTX) was administered (25 $\mu \mathrm{g}$, intraperitoneally) 3 days prior to removal of the vagus nerves for the isolated vagal nerve recording experiments.

The vagus nerve was dissected from human donor en bloc lungs unsuitable for transplantation (obtained from the International Institute for the Advancement of Medicine, Edison, NJ, USA), except in one case where the vagus nerve was dissected from lung tissue of a lung transplant recipient (obtained from the Royal Brompton \& Harefield NHS Foundation Trust, London, UK). Samples were from nine patients (seven males and two females; median (range) age 51 (27-67) years) with no history of respiratory disease, except the recipient sample that was from a cystic fibrosis patient. In all cases tissue was consented for use in scientific research. Ethics approval was obtained from the Royal Brompton \& Harefield NHS Foundation Trust.

\section{In vivo single-fibre recording}

Guinea pigs were anesthetised with urethane $\left(1.5 \mathrm{~g} \cdot \mathrm{kg}^{-1}\right.$, i.p. $)$ supplemented with additional urethane as required. The trachea was cannulated to maintain blood gases and $\mathrm{pH}$ at physiological levels by means of artificial ventilation, with tidal volume $10 \mathrm{~mL} \cdot \mathrm{kg}^{-1}$ and $50-60$ breaths $\cdot \mathrm{min}^{-1}$ of laboratory air. A cannula was connected to an air pressure transducer (SenSym 647; Farnell, Leeds, UK) with a side-arm to a monitor to measure tracheal pressure. The right jugular vein and carotid artery were cannulated for injecting drugs and measuring systemic arterial blood pressure, respectively. Animals were paralysed by (intravenous) administration of vecuronium bromide; initially at $100 \mu \mathrm{g} \cdot \mathrm{kg}^{-1}$, i.v., and maintained with $50 \mu \mathrm{g} \cdot \mathrm{kg}^{-1}$ every $20 \mathrm{~min}$. A cervical incision was made to locate both vagus nerves, which were cleared from the carotid artery and cut at the central end. The left vagus nerve was teased down until a single-fibre unit firing could be recorded using platinum electrodes. C-fibres used for these experiments were identified by the lack of spontaneous discharge and responsiveness to hyperinflation and deflation, responsiveness to capsaicin/citric acid administration, and possessing a conduction velocity $<1 \mathrm{~m} \cdot \mathrm{s}^{-1}$ $[2,17]$. Upon identification of a C-fibre, the experimental protocol was as follows: stimuli (capsaicin $100 \mu \mathrm{M}$ for $15 \mathrm{~s}$ or citric acid $300 \mathrm{mM}$ for $60 \mathrm{~s}$ ) were administered as aerosols to provoke action potential firing, with time between stimulations to allow recovery to baseline activity levels. PEA $\left(10 \mathrm{mg} \cdot \mathrm{kg}^{-1}\right.$, i.p. $)$ was then administered and then 30 min later the same stimuli were administered to evaluate the effect of PEA on action potential firing.

\section{Imaging of intracellular calcium in isolated airway neurons}

Dissection of jugular ganglia, dissociation of neurons from tissue, identification of airway terminating neurons and assessment of intracellular free calcium $\left[\mathrm{Ca}^{2+}\right]_{\mathrm{i}}$ levels using the fluorophore Fura-2 AM were carried out as described previously $[2,18] .50 \mathrm{mM}$ potassium chloride solution was applied at the start and end of each experiment for $10 \mathrm{~s}$ to assess cell viability and normalise responses. Neurons were stimulated twice with low $\mathrm{pH}(\mathrm{pH} 6)$ or capsaicin $(100 \mathrm{nM})$ for 1 min before vehicle or PEA $(1 \mathrm{nM})$ was applied for $10 \mathrm{~min}$. Stimulation was then re-assessed in the presence of vehicle or PEA. The criterion for a "responsive cell" was judged as an increase in $\left[\mathrm{Ca}^{2+}\right]_{\mathrm{i}}$ of $\geqslant 10 \%$ of the response to the $50 \mathrm{mM}$ potassium chloride solution.

\section{Compounds, materials and solutions}

PF-04862853 (7-azaspiro[3.5]nonane urea) [14] was kindly supplied by Pfizer Global R\&D (Cambridge, UK). SR141716A and SR144528 were purchased from Tocris Bioscience (Bristol, UK), and LEA was purchased from Cambridge Bioscience (Cambridge, UK). Fura-2 AM was purchased from Invitrogen (Paisley, UK). L-15 and Hanks' balanced salt solution were purchased from Gibco/Invitrogen (Carlsbad, CA, USA). All reagents not mentioned above were purchased from Sigma-Aldrich (St Louis, MO, USA).

For calcium imaging experiments, $50 \mathrm{mM}$ potassium solution contained $50 \mathrm{mM} \mathrm{KCl}, 91.4 \mathrm{mM} \mathrm{NaCl}$, $1 \mathrm{mM} \mathrm{MgCl}_{2}, 2.5 \mathrm{mM} \mathrm{CaCl}_{2}, 0.33 \mathrm{mM} \mathrm{NaH}_{2} \mathrm{PO}_{4}, 10 \mathrm{mM}$ glucose, $10 \mathrm{mM}$ HEPES; $\mathrm{pH}$ adjusted to 7.4 at $37^{\circ} \mathrm{C}$ using $\mathrm{KOH}$. For in vitro whole vagus and calcium imaging experiments, capsaicin and PEA were dissolved in 100\% dimethylsulfoxide (DMSO) and solutions were diluted 1:1000 in the perfusing solution. This was Krebs-Henseleit solution [16] for vagus experiments and extracellular solution $(5.4 \mathrm{mM} \mathrm{KCl}$, $136 \mathrm{mM} \mathrm{NaCl}, 1 \mathrm{mM} \mathrm{MgCl}$, $2.5 \mathrm{mM} \mathrm{CaCl}_{2}, 0.33 \mathrm{mM} \mathrm{NaH} \mathrm{PO}_{4}, 10 \mathrm{mM}$ glucose, $10 \mathrm{mM}$ HEPES; pH 
adjusted to 7.4 at $37^{\circ} \mathrm{C}$ using $\mathrm{NaOH}$ ) for calcium imaging experiments. Final vehicle concentration for an individual drug was $0.1 \%$, or up to $0.3 \%$ when combinations of drugs were perfused together.

\section{Data analysis and statistics}

A p-value of $<0.05$ was considered significant. Significance was assessed by the paired t-test (where comparisons are made in the presence of drug and compared with initial control responses on the same preparation), or by either the Mann-Whitney U-test or Kruskal-Wallis with Dunn's post hoc analysis (depending on the number of treatment columns), as indicated in the figure legends.

\section{Results}

PF-04862853 inhibits FAAH, elevates FAAs and inhibits cough in a conscious guinea pig model

PF-04862853 is known to achieve peak drug levels at $4 \mathrm{~h}$ post-dose, and demonstrates good oral bioavailability of $53 \%$ and $33 \%$ in rats and dogs, respectively $[14,15]$. Our results in guinea pig paralleled these findings, with peak levels of PF-04682853 (1 mg.kg ${ }^{-1}$, p.o.) occurring 2-4 h post-dose (figure 1a); we chose the $4 \mathrm{~h}$ time-point for further evaluations. PF-04862853 (1 mg.kg-1, p.o.) significantly inhibited citric acid-evoked cough (figure $1 \mathrm{~b}$ ). This dose caused robust inhibition of FAAH activity in the same animals ( $84 \%$, similar to previous studies in rats and dogs [15]) with concomitant elevations in plasma AEA, PEA, OEA and LEA ( 4-7-fold; figure 1c). These data indicate that the antitussive activity of the FAAH inhibitor is associated with peak PF-04862853 levels, FAAH enzyme inhibition and elevation of FAAs.
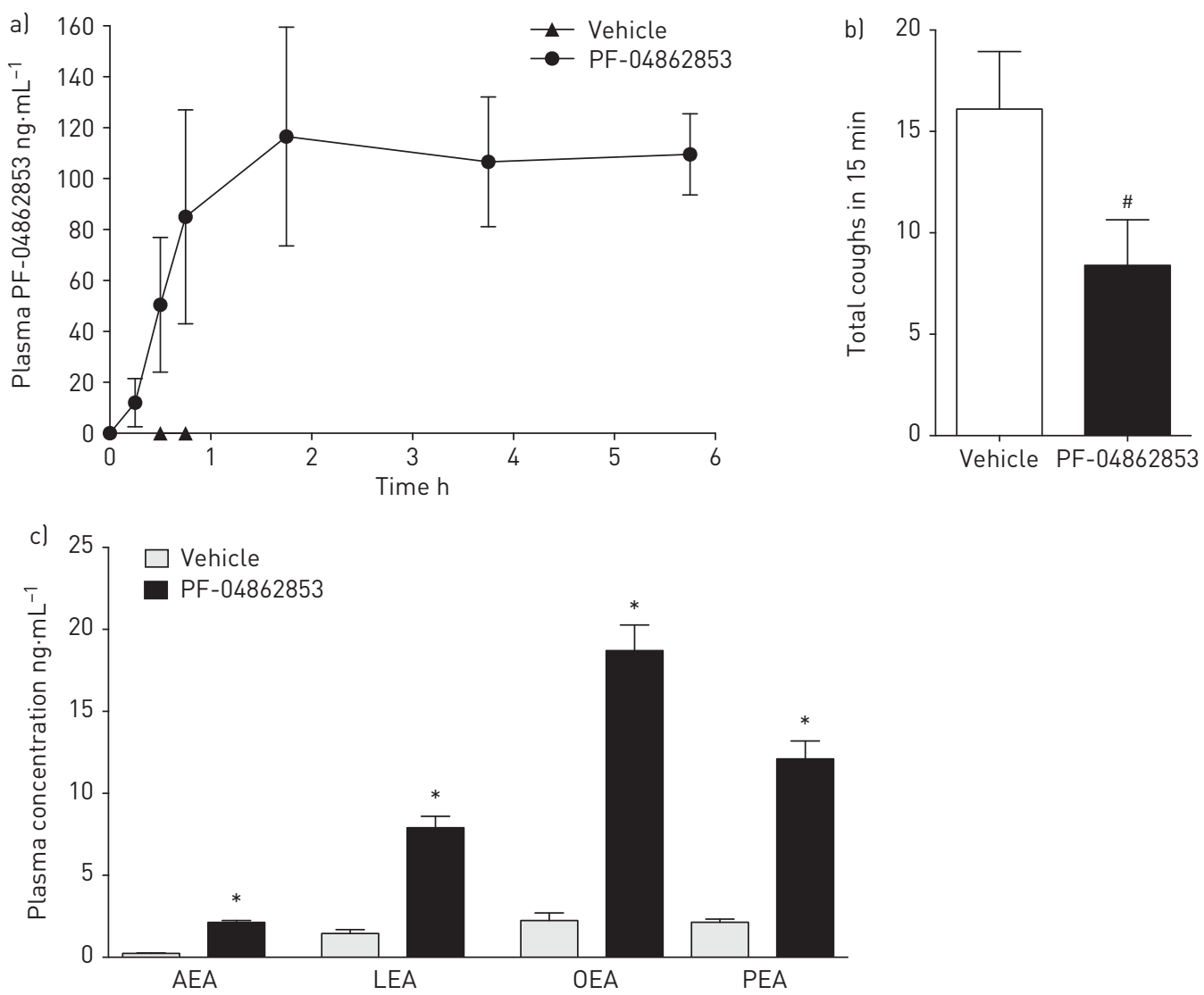

FIGURE 1 Oral dosing of PF-04862853 leads to elevation of fatty acid amides (FAAs) and inhibition of citric acid-evoked cough. AEA: N-arachidonoylethanolamide; LEA: linoleoylethanolamide; OEA: N-oleoylethanolamide; PEA: palmitoylethanolamide. a) Plasma levels of PF-04862853 at time-points after $1 \mathrm{mg} \cdot \mathrm{kg}^{-1}$, p.o. b) Effect of PF-0 $4862853\left(1 \mathrm{mg} \cdot \mathrm{kg}^{-1}\right.$, p.o., $4 \mathrm{~h}$ post-dose) on the number of coughs evoked by $0.3 \mathrm{M}$ citric acid. c) Plasma levels of the FAAs AEA, LEA, OEA and PEA following administration of PF-04862853 ( $1 \mathrm{mg} \cdot \mathrm{kg}^{-1}$, p.o., $4 \mathrm{~h}$ post-dose). Vehicle: $0.5 \%$ methylcellulose $/ 0.1 \%$ Tween 80 in saline. Data are presented as mean \pm SEM, $n=8$ animals per group. Compared with vehicle control group: * $p<0.05$ (MannWhitney U-test); ${ }^{*}: p<0.05$ (paired t-test). 
FAAs inhibit guinea pig isolated vagus nerve depolarisation via the $\mathrm{CB}_{2}$ receptor

We examined the effects of PEA, AEA, OEA and LEA on tussive stimuli-induced depolarisation of guinea pig isolated vagus nerve. PEA $(1 \mathrm{nM}$ to $1 \mu \mathrm{M})$ caused a concentration-related inhibition of both low $\mathrm{pH}$ and capsaicin-induced depolarisation of isolated guinea pig vagus nerve (figure $2 \mathrm{a}$ and $\mathrm{b}$ ). At a concentration of $100 \mathrm{nM}$ (submaximal for PEA), all four FAAs caused substantial inhibition (60-80\%) of
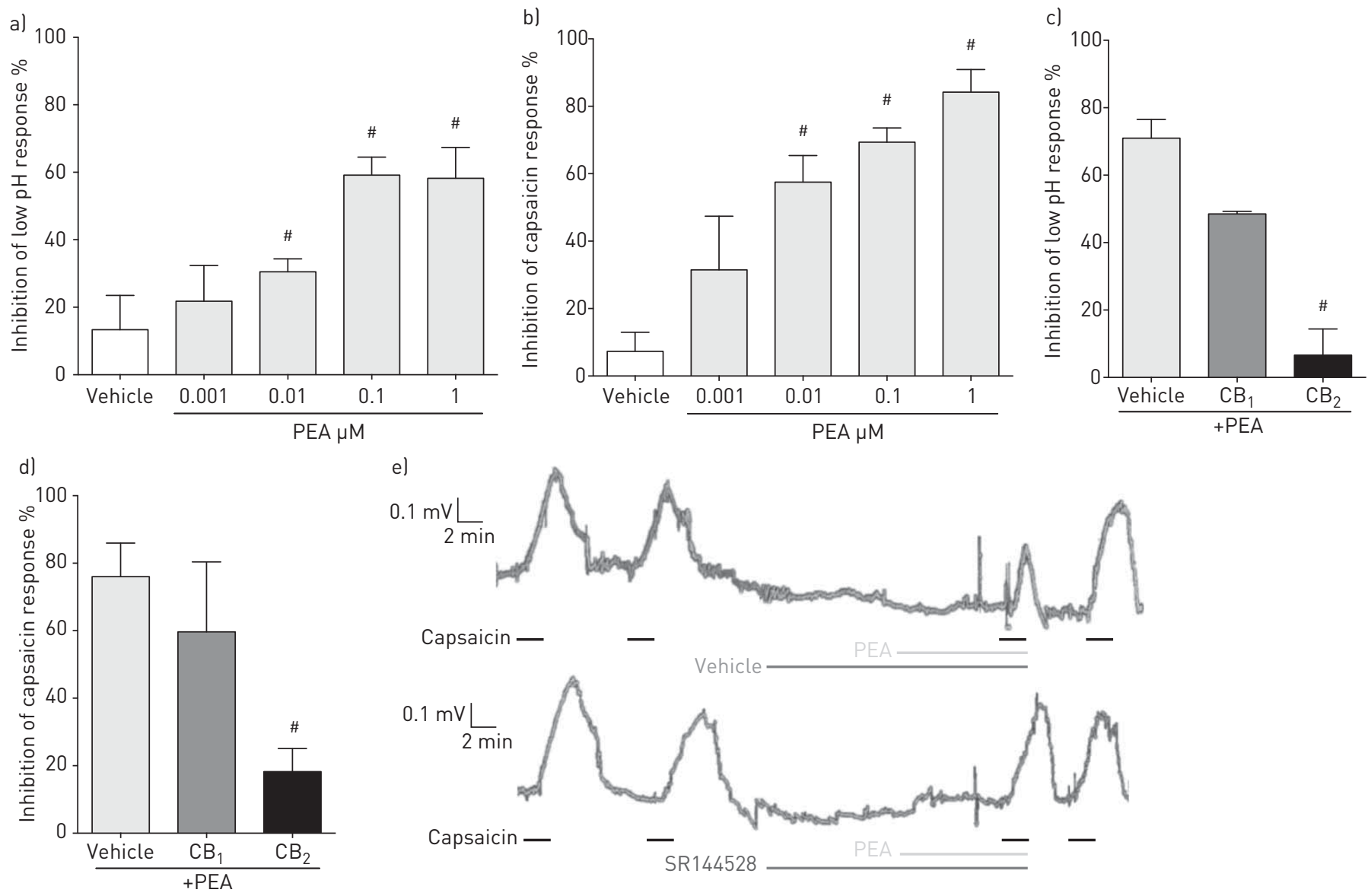

e)
$0.1 \mathrm{mV} \mathrm{L}_{2 \mathrm{~min}}$
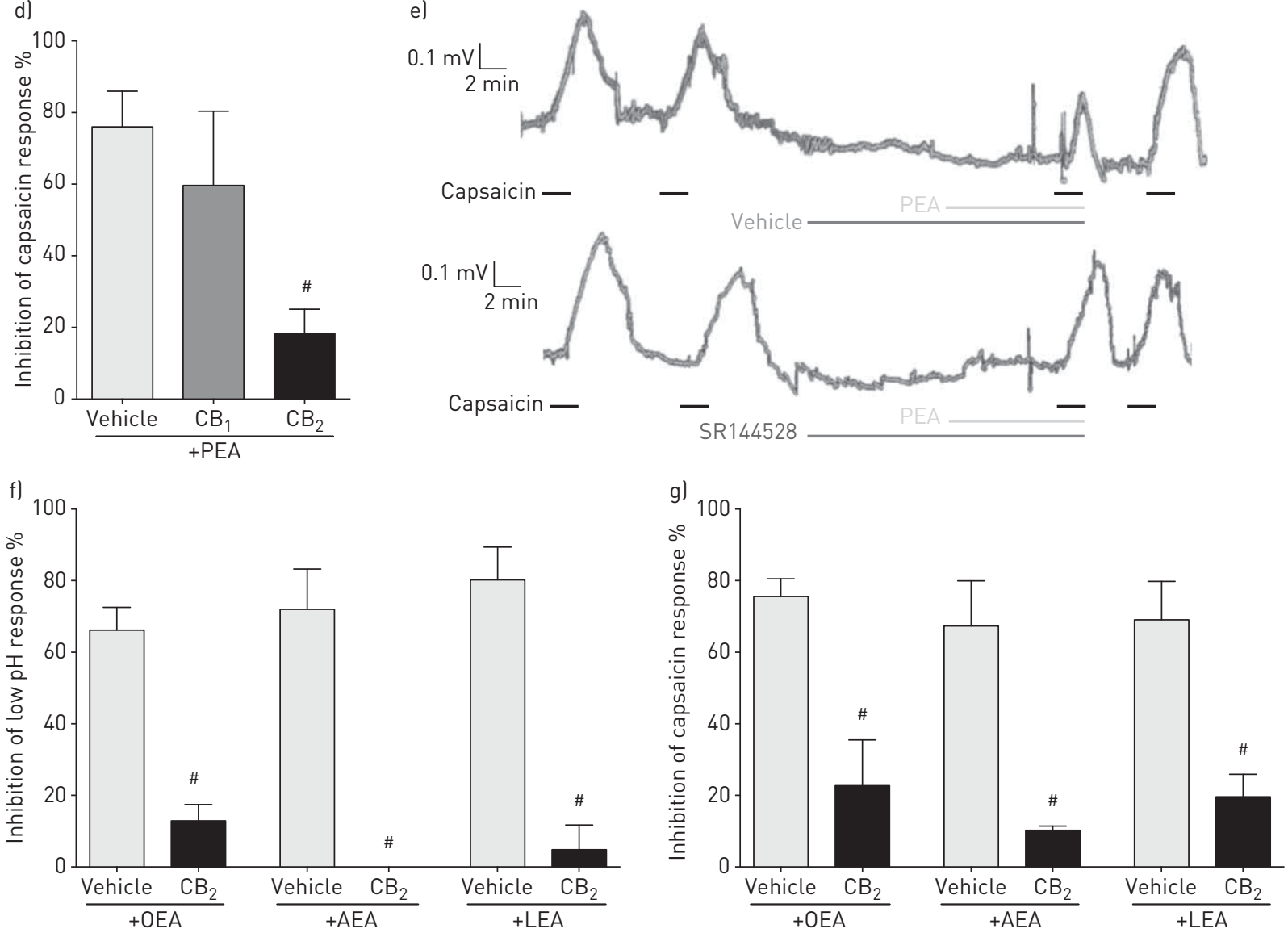

FIGURE 2 Palmitoylethanolamide (PEA) and other fatty acid amides inhibit low $\mathrm{pH}$ - and capsaicin-induced vagus nerve depolarisation via activation of cannabinoid $\mathrm{CB}_{2}$ receptors. OEA: $N$-oleoylethanolamide; $\mathrm{AEA}$ : $N$-arachidonoylethanolamide; LEA: linoleoylethanolamide. a, b) Concentration-related inhibition by PEA of depolarisation of the isolated guinea pig vagus evoked by a) low pH (pH 5) or b) capsaicin (1 $\mu$ M). c-e) Effect of CB, (SR141716A; $10 \mathrm{nM})$ and $\mathrm{CB}_{2}$ (SR144528; $\left.10 \mathrm{nM}\right)$ receptor antagonists on PEA (100 nM) inhibition of c) low $\mathrm{pH}$ (pH 5)- or d) capsaicin (1 $\left.\mu \mathrm{M}\right)$-induced depolarisation of guinea pig vagus, with el showing representative traces of experiments with vehicle or $\mathrm{CB}_{2}$ antagonist effect on $\mathrm{PEA}$ inhibition of capsaicin responses. $f, g$ ) Effect of $\mathrm{CB}_{2}$ (SR144528; $10 \mathrm{nM}$ ) receptor antagonist on OEA, AEA or LEA (100 nM) inhibition of f) low pH (pH 5)- or g) capsaicin $(1 \mu \mathrm{M})$-induced depolarisation of guinea pig isolated vagus nerve. Vehicle: $0.1 \% \mathrm{v} / \mathrm{v}$ dimethylsulfoxide. Data are presented as mean \pm SEM, $\mathrm{n}=4$ nerves from individual animals per group. Compared with vehicle control group: ${ }^{\#}: \mathrm{p}<0.05$ (Mann-Whitney U-test or Kruskal-Wallis with Dunn's post hoc analysis). 
the depolarisation induced by low $\mathrm{pH}$ and capsaicin, which was significantly reversed by the $\mathrm{CB}_{2}$ receptor antagonist SR144528 but not by the $\mathrm{CB}_{1}$ receptor antagonist SR141716A (figure 2c-g).

\section{PEA inhibits single-fibre firing in vivo and calcium influx in vitro in airway innervating nerves/} neurons

PEA $\left(10 \mathrm{mg} \cdot \mathrm{kg}^{-1}\right.$, i.p.) significantly reduced both total action potential firing and firing frequency of single airway innervating C-fibres in response to activation with either an aerosol of citric acid (0.3 M) or capsaicin $(100 \mu \mathrm{M})$ (figure $3 \mathrm{a}-\mathrm{c}$ ).

We also utilised an in vitro preparation, whereby we examined intracellular calcium flux in isolated jugular ganglion neurons stained with the retrograde tracer dye DiI, administered intranasally in vivo, to identify airway terminating neutrons in vitro. PEA $(1 \mathrm{nM})$ significantly abrogated the intracellular calcium signal induced by either low external $\mathrm{pH}(\mathrm{pH}$ ) or by capsaicin $(1 \mu \mathrm{M})$ in vitro in jugular ganglia neurons stained with DiI (indicating airway innervating neurons) (figure $4 \mathrm{a}-\mathrm{d}$ ).

\section{PEA inhibits guinea pig isolated vagus nerve depolarisation via the $G_{i / o}$ signalling pathway and} effects on calcium-activated potassium channels

PTX was utilised to block signal transduction via $\mathrm{G}_{\mathrm{i} / \mathrm{o}}$ subunits. In guinea pigs dosed with PTX, PEA inhibition of capsaicin-induced depolarisation was greatly abrogated compared with PEA inhibition in vagus nerves from vehicle-dosed control animals, indicating a role for $G_{i / o}$ signalling (figure 5a). Cannabinoid effects are often suggested to be at least partially mediated by effects on potassium channels; therefore, we examined the effect of various potassium channel blockers on PEA inhibition of vagus nerve depolarisation. Clotrimazole, paxilline and glibenclamide, blockers of intermediate $\left(\mathrm{IK}_{\mathrm{Ca}}\right)$ and large $\left(\mathrm{BK}_{\mathrm{Ca}}\right)$ conductance calcium-activated and ATP-sensitive $\left(\mathrm{K}_{\mathrm{ATP}}\right)$ potassium channels, respectively, had no significant effect on the inhibitory effects of PEA on guinea pig vagus nerve depolarisation. By contrast, apamin $(1 \mu \mathrm{M})$, a blocker of small conductance $\left(\mathrm{SK}_{\mathrm{Ca}}\right)$ calcium-activated potassium channels, almost abolished PEA inhibition ( $85-90 \%)$ of capsaicin- and low $\mathrm{pH}$-induced depolarisation (figure 5b and c). Consistent with an activity on $\mathrm{SK}_{\mathrm{Ca}}$ channels, PEA inhibited depolarisation of guinea pig vagus nerve evoked by agonists of multiple excitatory ion channels examined (supplementary figure S1), i.e. the TRPA1
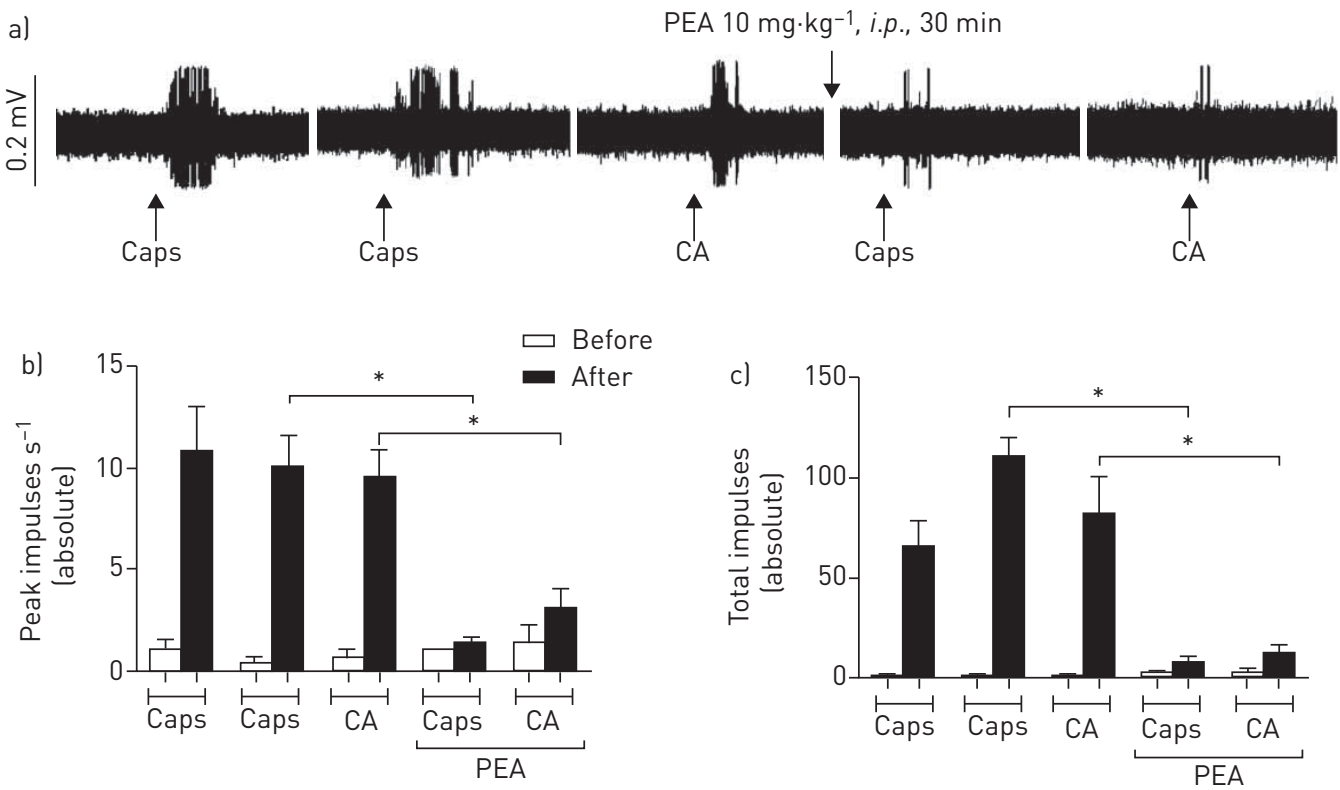

FIGURE 3 Palmitoylethanolamide (PEA) inhibits citric acid (CA)- and capsaicin (Caps)-evoked C-fibre firing in vivo. a) Representative trace showing single $\mathrm{C}$-fibre action potential firing to capsaicin $(100 \mu \mathrm{M})$ or citric acid $(0.3 \mathrm{M})$ aerosol for 15 and $60 \mathrm{~s}$, respectively, prior to and then in the presence of PEA $\left(10 \mathrm{mg} \cdot \mathrm{kg}^{-1}\right.$, i.p., $30 \mathrm{~min}$ prior to capsaicin challenge). b) Peak firing frequency and cl total impulses were assessed in guinea pig airway innervating $\mathrm{C}$-fibres in response to intratracheal aerosol administration of citric acid $(0.3 \mathrm{M})$ or capsaicin $(100 \mu \mathrm{M})$. Panels show spontaneous levels of firing immediately before and levels of firing after administration of citric acid or capsaicin. Control responses were established on each nerve before i.p. administration of PEA ( $10 \mathrm{mg} \cdot \mathrm{kg}^{-1}$ in vehicle $0.5 \%$ methylcellulose $/ 0.1 \%$ Tween 80 in saline $10 \mathrm{~mL} \cdot \mathrm{kg}^{-1}$ ). Data are presented as mean \pm SEM, $n=3$ nerve fibres in individual animals. Compared with respective control groups: *: $p<0.05$ (paired t-test). 


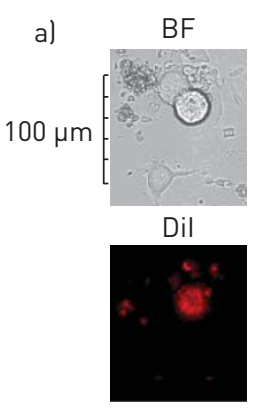

b)

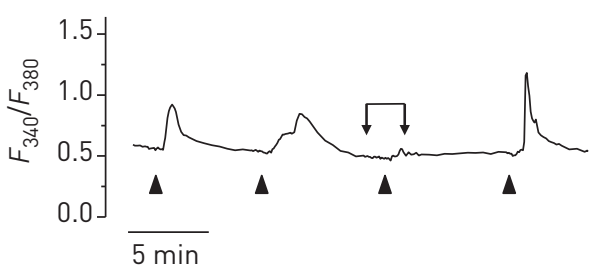

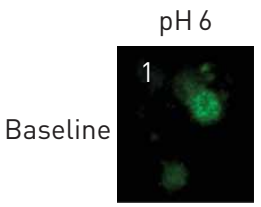

$\mathrm{pH} 6$
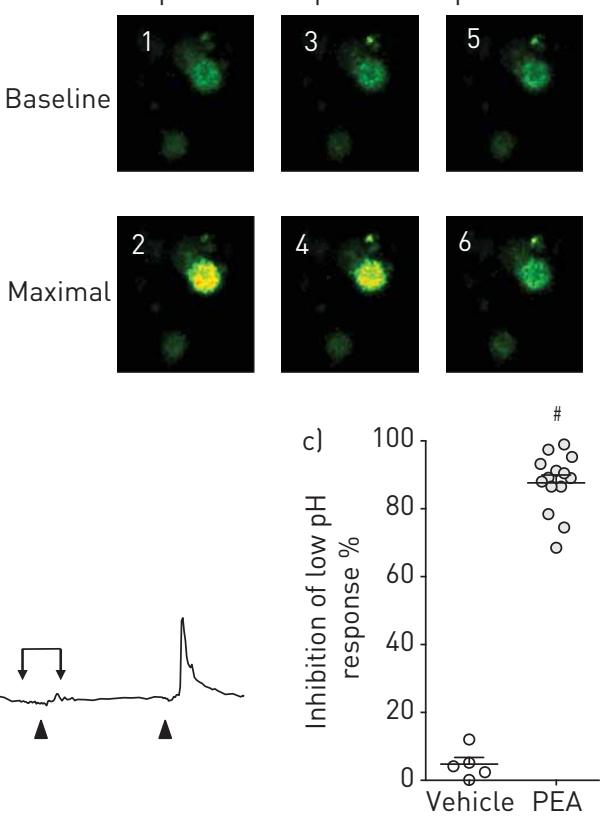
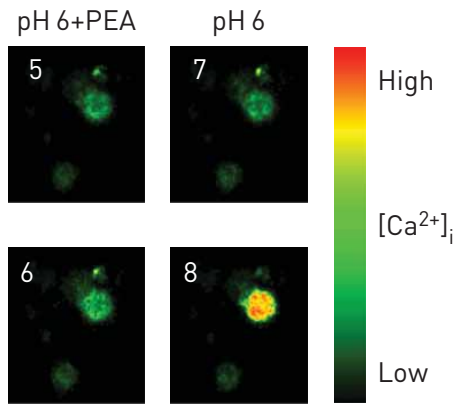

Low
FIGURE 4 Palmitoylethanolamide (PEA; $1 \mathrm{nM}$ ) inhibits low $\mathrm{pH}$ - and capsaicin-induced increases in intracellular calcium in airway neurons. a) Representative images showing brightfield (BF) image of neurons with Dil emission indicating an airway terminating neuron. Images 1-8 indicate levels of intracellular calcium pre- and post-pH 6 stimulation. b) Trace of quantified intracellular calcium levels in the same neuron/ experiment, with drug additions indicated by arrowheads $(\mathrm{pH} 6)$ and the brace/arrows $(\mathrm{PEA} ; 1 \mathrm{nM}) . F_{340} / F_{380}$ : ratio of the fluorescence intensities at 340 and $380 \mathrm{~nm}$ excitation. c, d) PEA (1 nM) inhibition of c) low pH (pH 6)- or d) capsaicin (100 nM)-induced intracellular calcium increases in isolated airway jugular neurons from guinea pigs. Data are presented as mean \pm SEM, $n=4-14$ cells per group, $N=3-4$ animals. Vehicle: $0.1 \% \mathrm{v} / \mathrm{v}$ dimethylsulfoxide. Compared with vehicle control group: ${ }^{\#}$ : $p<0.05$ (Mann-Whitney U-test).

agonist acrolein $(300 \mu \mathrm{M})$, the synthetic TRPV4 agonist GSK1016790A (300 nM) or the endogenous TRPV4 agonist hypo-osmotic solution (-80 mOsm).

As the $\mathrm{SK}_{\mathrm{Ca}}$ channel was implicated in the inhibitory actions of PEA, we examined the possible involvement of protein phosphatase $2 \mathrm{~A}(\mathrm{PP} 2 \mathrm{~A})$, which forms a regulatory part of the $\mathrm{SK}_{\mathrm{Ca}}$ channel multiprotein complex along with casein kinase II (CKII) and calmodulin (CaM). CaM is bound to the $\mathrm{SK}_{\mathrm{Ca}}$ channel and translates calcium binding into channel opening; CKII phosphorylation of CaM decreases $\mathrm{SK}_{\mathrm{Ca}}$ calcium sensitivity (and therefore open probability), whereas PP2A dephosphorylation of $\mathrm{CaM}$ increases calcium sensitivity [19]. A PP2A inhibitor (okadaic acid; $1 \mathrm{nM}$ ) blocked the inhibitory effects of PEA on vagus nerve depolarisation, whereas a CKII inhibitor (4,5,6,7-tetrabromobenzotriazole; $10 \mu \mathrm{M}$ ) inhibited depolarisation itself (figure $5 \mathrm{~d}$ ). These results suggest that PEA activates $\mathrm{SK}_{\mathrm{Ca}}$ channels by activation of $\mathrm{PP} 2 \mathrm{~A}$, which dephosphorylates $\mathrm{SK}_{\mathrm{Ca}}$-bound $\mathrm{CaM}$ to increase the channel's calcium sensitivity.

PEA inhibits human vagus nerve depolarisation via a $C B_{2}-P P 2 A-S K_{C a}$ channel mechanism

To increase the translational nature of this study we performed key experiments in a unique human vagal sensory nerve assay assessing depolarisation in a similar fashion to the guinea pig. PEA (100 nM) inhibited both low $\mathrm{pH}$ - and capsaicin-induced depolarisation of human vagus nerves by $\sim 70-80 \%$ (figure 6). Furthermore, PEA inhibition of depolarisation was completely reversed by the $\mathrm{CB}_{2}$ receptor antagonist but not the $\mathrm{CB}_{1}$ receptor antagonist (figure $6 \mathrm{~b}$ ) and substantially reversed $(\sim 85 \%)$ by the $\mathrm{SK}_{\mathrm{Ca}}$ channel blocker (apamin; $1 \mu \mathrm{M}$ ) (figure $6 \mathrm{c}$ ). In preliminary experiments $(\mathrm{n}=2)$, the PP2A inhibitor blocked the effects of PEA and an inhibitor of CKII mimicked the effects of PEA (figure 6d), suggesting PEA inhibition of human vagus nerve depolarisation is also mediated by the $\mathrm{CB}_{2}-\mathrm{PP} 2 \mathrm{~A}-\mathrm{SK} \mathrm{Ca}_{\mathrm{a}}$ channel pathway.

\section{Discussion}

Recent evidence suggests that $\mathrm{CB}_{2}$ receptors mediate inhibition of airway sensory nerve activity and cough in animal models, highlighting the $\mathrm{CB}_{2}$ receptor as a potential target for the treatment of cough $[6,7]$. However, cannabinoids are associated with a variety of central effects such as sedation, nausea and addiction, which limit their use as therapies [20,21]. The pharmacological blockade of FAAH has 

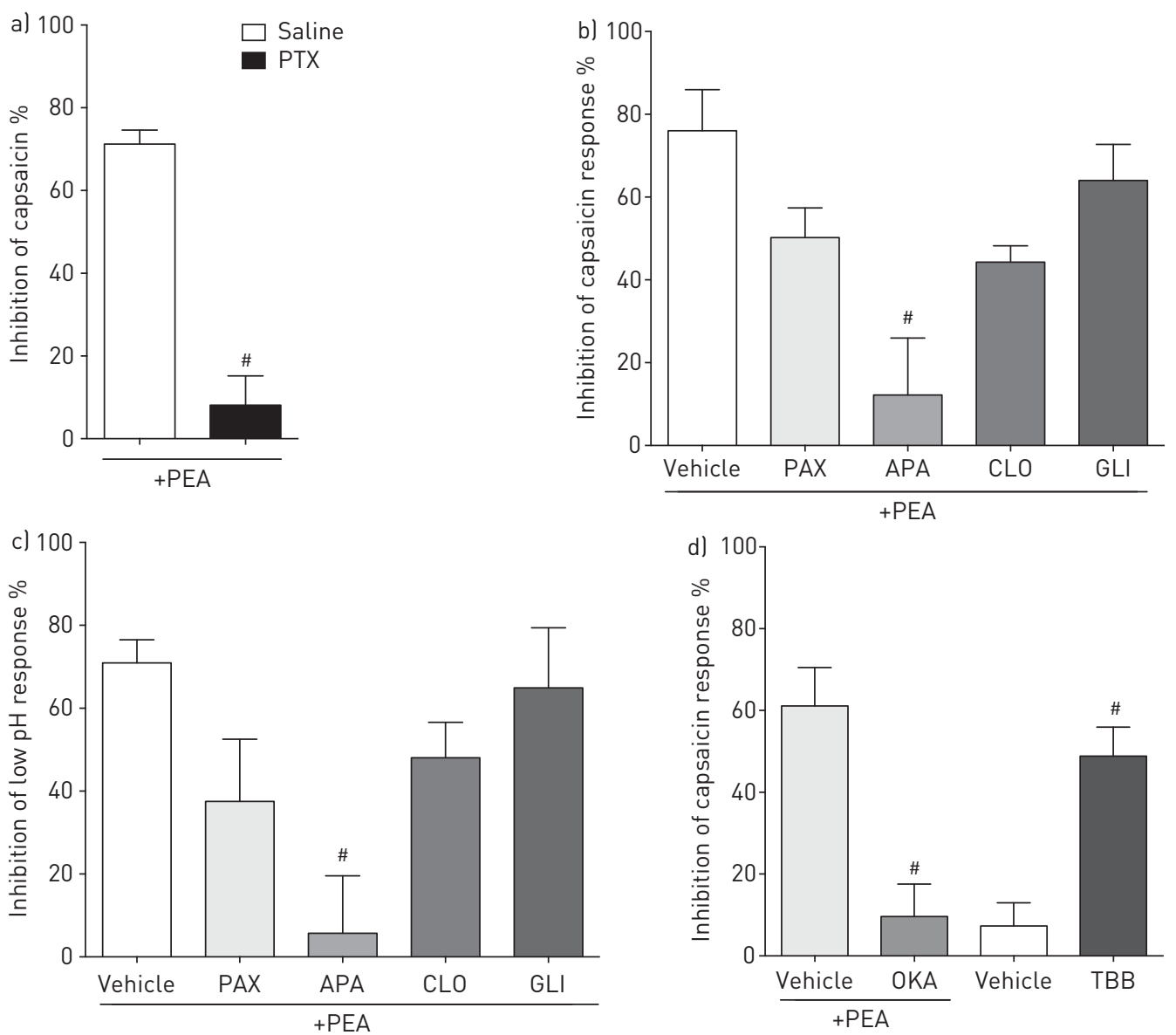

FIGURE 5 Palmitoylethanolamide (PEA) inhibits isolated vagus nerve depolarisation through a $\mathrm{CB}_{2} / \mathrm{G}_{\mathrm{i} / \mathrm{o}^{-}}$ coupled pathway and activation of small conductance calcium-activated potassium channels and phosphatase 2A. PTX: pertussis toxin; PAX: paxilline; APA: apamin; CLO: clotrimazole; GLI: glibenclamide; OKA: okadaic acid; TBB: 4,5,6,7-tetrabromobenzotriazole. a) Effect of PTX (dosed $25 \mu \mathrm{g}$, i.p., 3 days prior to the removal of nerve tissue) on PEA (100 nM) inhibition of capsaicin $(1 \mu \mathrm{M})$-induced depolarisation of guinea pig vagus nerve. $b, c)$ Effect of PAX $(1 \mu \mathrm{M})$, APA $(1 \mu \mathrm{M})$, CLO $(10 \mu \mathrm{M})$ or GLI $(10 \mu \mathrm{M})$ on PEA $(100 \mathrm{nM})$ inhibition of b) capsaicin $(1 \mu \mathrm{M})-$ and c) low $\mathrm{pH}(\mathrm{pH} 5)$-induced depolarisation of guinea pig vagus nerve. d) Effect of OKA (1 nM) on PEA $(100 \mathrm{nM})$ inhibition of capsaicin $(1 \mu \mathrm{M})$-induced depolarisation and effect of TBB $(10 \mu \mathrm{M})$ on capsaicin $(1 \mu \mathrm{M})$-induced depolarisation of isolated guinea pig vagus nerve. Vehicle: $0.1 \% \mathrm{v} / \mathrm{v}$ dimethylsulfoxide. Data are presented as mean \pm SEM, $n=3-4$ nerves from individual animals per group. Compared with relevant vehicle control group: " : p $<0.05$ (Mann-Whitney U-test or Kruskal-Wallis with Dunn's post hoc analysis).

emerged as a potentially attractive strategy by which endocannabinoid levels are elevated and retain the beneficial effects of cannabinoid receptor activation to relieve pain [22], while avoiding the undesirable effects of global cannabinoid receptor activation.

Over the past decade, there have been advances in the development of FAAH inhibitors and initial interest focused on developing FAAH inhibitors to augment the actions of FAAs and reduce pain. More recently, emerging literature has shown that these FAAs, through interactions with a variety of receptors (extracellular and intracellular), can induce a diverse array of effects that include appetite suppression, modulation of lipid and glucose metabolism, vasodilatation, cardiac function, and inflammation [22]. However, to the best of our knowledge, the effects of FAAH inhibitors have not been studied in the airways. We hypothesised that inhibition of FAAH by a selective inhibitor may have antitussive effects. The FAAH inhibitor used in this study (i.e. PF-04862853) is a recently developed compound shown to have excellent potency, selectivity, pharmacokinetic properties and in vivo efficacy in a model of inflammatory pain [15].

PF-04862853, examined $4 \mathrm{~h}$ post-dose, inhibited cough in guinea pigs and was associated with increases in the plasma levels of FAAs (PEA, AEA, OEA and LEA). Although there are several subclasses of FAAs, the endogenous FAAs identified in the present study belong to the $\mathrm{N}$-acylethanolamide subclass, and have been identified in mammalian tissues in the brain and in peripheral tissues [23-25]. These FAAs are 
a)
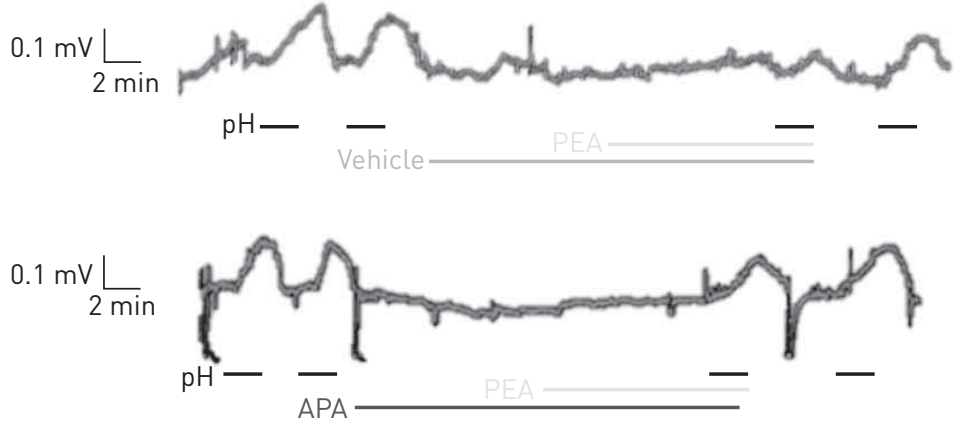

b)

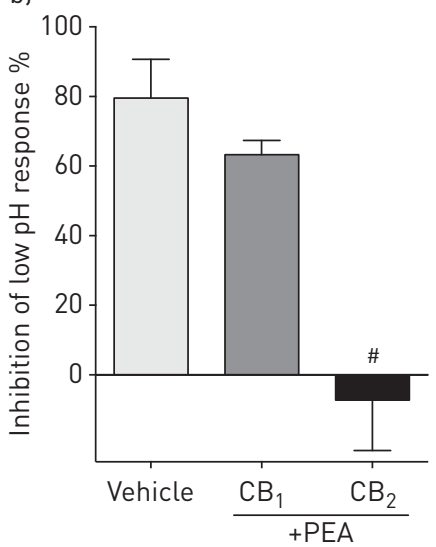

c)

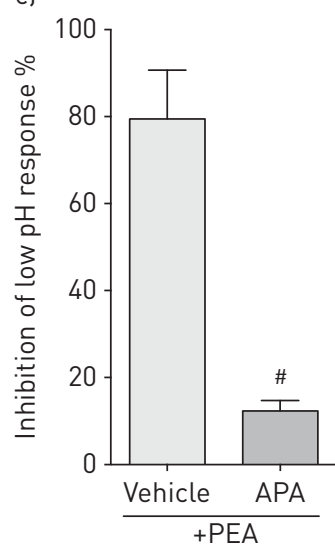

d)

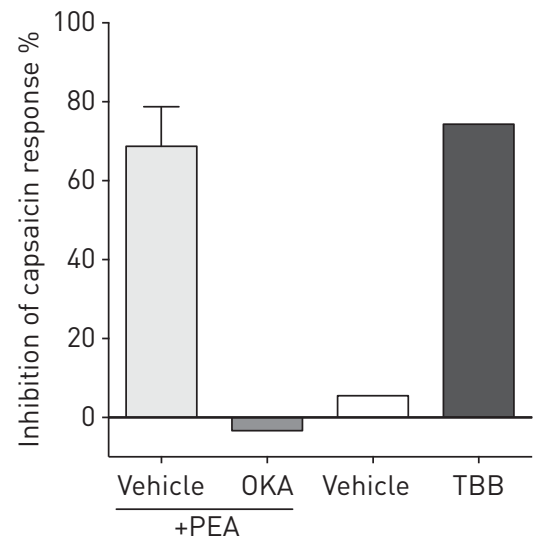

FIGURE 6 Palmitoylethanolamide (PEA) inhibits depolarisation in human vagus nerve via $\mathrm{CB}_{2}$-phosphatase 2A-small conductance calcium-activated potassium channel. APA: apamin; OKA: okadaic acid; TBB: 4,5,6,7-tetrabromobenzotriazole. a) Representative traces showing PEA inhibition of low $\mathrm{pH}$ responses in the presence of (top) vehicle or (bottom) APA $(1 \mu \mathrm{M})$. b) Effect of $\mathrm{CB}_{1}$ (SR141716A, $10 \mathrm{nM}$ ) and $\mathrm{CB}_{2}$ (SR144528, $10 \mathrm{nM})$ receptor antagonists on PEA (100 $\mathrm{nM})$ inhibition of $\mathrm{low} \mathrm{pH}(\mathrm{pH}$ 5)-induced depolarisation of human isolated vagus nerve. c) Effect of APA $(1 \mu \mathrm{M})$ on PEA $(100 \mathrm{nM})$ inhibition of low $\mathrm{pH}(\mathrm{pH}$ 5)-induced depolarisation of human isolated vagus nerve. d) Effect of OKA (1 nM) on PEA (100 nM) inhibition of capsaicin $(1 \mu \mathrm{M})$-induced depolarisation and effect of TBB on capsaicin $(1 \mu \mathrm{M})$-induced depolarisation of human isolated vagus nerve. Vehicle: $0.1 \% \mathrm{v} / \mathrm{v}$ dimethylsulfoxide. Data are presented as mean $\pm \mathrm{SEM}, \mathrm{n}=4$ nerves from individual animals per group, except where no SEM shown, $n=2$ nerves from individual animals. Compared with relevant vehicle control group: ${ }^{\#}$ : $p<0.05$ (Mann-Whitney U-test or Kruskal-Wallis with Dunn's post hoc analysis).

referred to as "endocannabinoids" because they can function as agonists of $\mathrm{CB}_{1}$ and $\mathrm{CB}_{2}$ receptors. Given that exogenous cannabinoids exert antitussive activity via action on $\mathrm{CB}_{2}$ receptors on sensory nerves $[6,7]$, we hypothesised that these FAAs mediate the antitussive effects of FAAH inhibition by likewise inhibiting sensory nerve activation via the $\mathrm{CB}_{2}$ receptor.

All the FAAs examined inhibited low $\mathrm{pH}$ - and capsaicin-evoked depolarisation of the guinea pig isolated vagus nerve, an effect reversed by the selective $\mathrm{CB}_{2}$ receptor antagonist, but not the $\mathrm{CB}_{1}$ receptor antagonist [26, 27]. Furthermore, PEA (used as the exemplar) also inhibited capsaicin- and citric acid-evoked action potential firing in guinea pig airway innervating C-fibres in vivo, and the intracellular calcium increases induced by capsaicin or low $\mathrm{pH}$ in isolated airway terminating guinea pig jugular neurons in vitro. The combination of these experiments strongly suggests that the FAAs elevated by FAAH inhibition act on $\mathrm{CB}_{2}$ receptors on sensory nerves to mediate the antitussive effects of PF-04862853. Furthermore, in vagus nerve tissue from PTX-treated animals, PEA inhibition was lost, suggesting engagement of $\mathrm{G}_{\mathrm{i} / \mathrm{o}}$ subunit signalling downstream of the $\mathrm{CB}_{2}$ receptor. Although our data utilising the vagus nerve preparation would indicate a peripheral mechanism of action, central effects of FAAs cannot be disregarded.

Although the FAAs examined have been reported to activate $\mathrm{CB}_{2}$ receptors [28-31], previous publications have also suggested effects on $\mathrm{CB}_{1}$ receptors [29], PPAR (PPAR- $\alpha,-\beta$ and $-\gamma$ ) receptors [10, 31-33], and TRPV1 [9, 34, 35] and TRPM8 [36] ion channels. However, a role for $\mathrm{CB}_{2}$ receptors has been clearly identified in these studies, which utilised highly selective pharmacological tools [26, 27], that is consistent with previous studies $[6,7]$. However, it is still impossible to completely rule out a contribution from noncannabinoid receptors to the in vivo activity of FAAs. 
Apamin, an inhibitor of $\mathrm{SK}_{\mathrm{Ca}}$ channels, blocked the inhibition by PEA of depolarisation of the guinea pig isolated vagus nerve, confirming previous reports that $\mathrm{CB}_{1}$ and $\mathrm{CB}_{2}$ receptor agonists can activate potassium channels [37]. $\mathrm{SK}_{\mathrm{Ca}}$ channels are one of a family of calcium-activated potassium channels and their activation causes potassium efflux from neurons, thereby decreasing their excitability. The $\mathrm{SK}_{\mathrm{Ca}}$ channel is part of a multiprotein complex along with CaM, PP2A and CKII. CaM is bound to the $\mathrm{SK}_{\mathrm{Ca}}$ channel and plays a key role in translating calcium binding into channel opening. The sensitivity of CaM, and therefore of the $\mathrm{SK}_{\mathrm{Ca}}$ channel, to calcium is regulated by phosphorylation/dephosphorylation, with phosphorylation by CKII resulting in decreased calcium sensitivity and dephosphorylation by PP2A resulting in increased calcium sensitivity [19]. Our finding that okadaic acid, a PP2A inhibitor, blocks the inhibitory activity of PEA on vagus nerves suggests that PEA acts to increase the sensitivity to calcium (and therefore the activity) of the $\mathrm{SK}_{\mathrm{Ca}}$ channel via activation of PP2A. Key datasets were repeated in human vagus nerve preparations with similar results obtained compared with guinea pig.

In conclusion, inhibition of FAAH produces antitussive activity in conscious guinea pigs. Our data indicate that this effect could be mediated by elevated FAAs, acting on cannabinoid $\left(\mathrm{CB}_{2}\right)$ receptors on vagal sensory nerves, leading to activation of $\mathrm{SK}_{\mathrm{Ca}}$ channels, an effect that translates to human vagus nerves. To date, interest in this area has focused on developing FAAH inhibitors to reduce pain, and early clinical studies have indicated that a closely related analogue (i.e. PF-04457845) to the compound investigated here was well tolerated with no effect on cognitive functions at doses exceeding those required for maximal inhibition of FAAH activity and elevation of FAAs [38]. These data suggest that inhibition of FAAH with consequent elevation of FAAs could be an interesting and novel therapeutic approach to treat chronic cough. Although efficacy in pre-clinical and clinical capsaicin challenge studies (e.g. utilising TRPV1 antagonists) has not translated to efficacy in chronic cough patients, the fact that FAA ligands inhibit depolarisation of the vagus evoked by agonists of multiple excitatory ion channels gives a broader chance of success [39-41]. With clinical-ready compounds available, proof-of-concept clinical studies could be undertaken by adopting a re-positioning approach and utilising compounds from the arena of pain therapeutics. This strategy was successful recently with the P2X3 inhibitor AF-219, which was found to demonstrate unprecedented efficacy in chronic cough in treatment-resistant patients [42].

\section{Acknowledgements}

Author contributions: M.A. Wortley, J.J. Adcock, R. Kinloch, G. McMurray, C. Perros-Huguet, M. Papakosta, M.A. Birrell and M.G. Belvisi made substantial contributions to the conception or design of the work. M.A. Wortley, J.J. Adcock, E.D. Dubuis, S.A. Maher, S.J. Bonvini, I. Delescluse, M.A. Birrell and M.G. Belvisi made contributions to the acquisition, analysis or interpretation of data for the work. All authors participated in drafting the work or revising it critically for important intellectual content and in final approval of the version to be published, and agree to be accountable for all aspects of the work in ensuring that questions related to the accuracy or integrity of any part of the work are appropriately investigated and resolved.

\section{References}

1 Ford AC, Forman D, Moayyedi P, et al. Cough in the community: a cross sectional survey and the relationship to gastrointestinal symptoms. Thorax 2006; 61: 975-979.

2 Bonvini SJ, Birrell MA, Smith JA, et al. Targeting TRP channels for chronic cough: from bench to bedside. Naunyn Schmiedebergs Arch Pharmacol 2015; 388: 401-420.

3 Haque RA, Usmani OS, Barnes PJ. Chronic idiopathic cough: a discrete clinical entity? Chest 2005; 127: $1710-1713$.

4 Schroeder K, Fahey T. Systematic review of randomised controlled trials of over the counter cough medicines for acute cough in adults. BMJ 2002; 324: 329-331.

5 Canning BJ, Mori N, Mazzone SB. Vagal afferent nerves regulating the cough reflex. Respir Physiol Neurobiol 2006; 152: 223-242.

6 Patel HJ, Birrell MA, Crispino N, et al. Inhibition of guinea-pig and human sensory nerve activity and the cough reflex in guinea-pigs by cannabinoid $\left(\mathrm{CB}_{2}\right)$ receptor activation. Br J Pharmacol 2003; 140: 261-268.

7 Belvisi MG, Patel HJ, Freund-Michel V, et al. Inhibitory activity of the novel $\mathrm{CB}_{2}$ receptor agonist, GW833972A, on guinea-pig and human sensory nerve function in the airways. Br J Pharmacol 2008; 155: 547-557.

8 Ahn K, Johnson DS, Cravatt BF. Fatty acid amide hydrolase as a potential therapeutic target for the treatment of pain and CNS disorders. Expert Opin Drug Discov 2009; 4: 763-784.

9 Hovarth G, Kekesi G, Nagy E, et al. The role of TRPV1 receptors in the antinociceptive effect of anandamide at spinal level. Pain 2008; 134: 277-284.

10 Verme JL, Astarita FG, La Rana L, et al. The nuclear receptor peroxisome proliferator-activated receptor-alpha mediates the anti-inflammatory actions of palmitoylethanolamide. Mol Pharmacol 2005; 67: 15-19.

11 Chang L, Luo L, Palmer JA, et al. Inhibition of fatty acid amide hydrolase produces analgesia by multiple mechanisms. Br J Pharmacol 2006; 148: 102-113.

12 Schlosburg JE, Kinsey SG, Lichtman AH. Targeting fatty acid amide hydrolase (FAAH) to treat pain and inflammation. AAPS J 2009; 11: 39-44.

13 Kilkenny C, Browne WJ, Cuthill IC, et al. Improving bioscience research reporting: the ARRIVE guidelines for reporting animal research. PLoS Biol 2010; 8: e1000412.

14 Meyers MJ, Long SA, Pelc M), et al. Discovery of novel spirocyclic inhibitors of fatty acid amide hydrolase (FAAH). Part 2. Discovery of 7-azaspiro[3.5]nonane urea PF-04862853, an orally efficacious inhibitor of fatty acid amide hydrolase (FAAH) for pain. Bioorg Med Chem Lett 2011; 21: 6545-6553. 
15 Ahn K, Johnson DS, Mileni M, et al. Discovery and characterization of a highly selective FAAH inhibitor that reduces inflammatory pain. Chem Biol 2009; 16: 411-420.

16 Dubuis E, Wortley MA, Grace MS, et al. Theophylline inhibits the cough reflex through a novel mechanism of action. J Allergy Clin Immunol 2014; 133: 1588-1598.

17 Adcock JJ, Douglas GJ, Garabette M, et al. RSD931, a novel anti-tussive agent acting on airway sensory nerves. Br J Pharmacol 2003; 138: 407-416.

18 Dubuis E, Grace M, Wortley MA, et al. Harvesting, isolation, and functional assessment of primary vagal ganglia cells. Curr Protoc Pharmacol 2013; 62: 12.15.

19 Allen D, Fakler B, Maylie J, et al. Organization and regulation of small conductance $\mathrm{Ca}^{2+}$-activated $\mathrm{K}^{+}$channel multiprotein complexes. J Neurosci 2007; 27: 2369-2376.

20 Miller LK, Devi LA. The highs and lows of cannabinoid receptor expression in disease: mechanisms and their therapeutic implications. Pharmacol Rev 2011; 63: 461-470.

21 Pertwee RG, Howlett AC, Abood ME, et al. International Union of Basic and Clinical Pharmacology. LXXIX. Cannabinoid receptors and their ligands: beyond $\mathrm{CB}_{1}$ and $\mathrm{CB}_{2}$. Pharmacol Rev 2010; 62: 588-631.

22 Pillarisetti, S, Alexander CW, Khanna I. Pain and beyond: fatty acid amides and fatty acid amide hydrolase inhibitors in cardiovascular and metabolic diseases. Drug Discov Today 2009; 14: 1098-1111.

23 Palmer SL, Thakur GA, Makriyannis A. Cannabinergic ligands. Chem Phys Lipids 2002; 121: 3-19.

24 Mechoulam R, Fride E, Di Marzo V. Endocannabinoids. Eur J Pharmacol 1998; 359: 1-18.

25 Koga D, Santa T, Fukushima T, et al. Liquid chromatographic-atmospheric pressure chemical ionization mass spectrometric determination of anandamide and its analogs in rat brain and peripheral tissues. $J$ Chromatogr $B$ Biomed Sci Appl 1997; 690: 7-13.

26 Rinaldi-Carmona M, Barth F, Millan J, et al. SR144528, the first potent and selective antagonist of the CB2 cannabinoid receptor. J Pharmacol Exp Ther 1998; 284: 644-650.

27 Rinaldi-Carmona M, Barth F, Heaulme M, et al. SR141716A, a potent and selective antagonist of the brain cannabinoid receptor. FEBS Lett 1994; 350: 240-244.

28 Vaia M, Petrosino S, De Filippis D, et al. Palmitoylethanolamide reduces inflammation and itch in a mouse model of contact allergic dermatitis. Eur J Pharmacol 2016; 791: 669-674.

29 Aghaei I, Rostampour M, Shabani M, et al. Palmitoylethanolamide attenuates PTZ-induced seizures through CB1 and CB2 receptors. Epilepsy Res 2015; 117: 23-28.

30 AlSuleimani YM, Hiley CR. Mechanisms of vasorelaxation induced by oleoylethanolamide in the rat smal mesenteric artery. Eur J Pharmacol 2013; 702: 1-11.

$31 \mathrm{Xu} \mathrm{X}$, Guo $\mathrm{H}$, Jing Z, et al. $\mathrm{N}$-oleoylethanolamine reduces inflammatory cytokines and adhesion molecules in TNF- $\alpha$-induced human umbilical vein endothelial cells by activating $\mathrm{CB}_{2}$ and PPAR- $\alpha$. J Cardiovasc Pharmacol 2016; 68: 280-291.

32 O'Sullivan, SE. Cannabinoids go nuclear: evidence for activation of peroxisome proliferator-activated receptors. $\mathrm{Br}$ J Pharmacol 2007; 152: 576-582.

33 Fu J, Gaetani S, Oveisi F, et al. Oleylethanolamide regulates feeding and body weight through activation of the nuclear receptor PPAR-alpha. Nature 2003; 425: 90-93.

34 Ho WS, Barrett DA, Randall MD. 'Entourage' effects of $N$-palmitoylethanolamide and $N$-oleoylethanolamide on vasorelaxation to anandamide occur through TRPV1 receptors. Br J Pharmacol 2008; 155: 837-846.

35 Movahed P, Jönsson BA, Birnir B, et al. Endogenous unsaturated C18 N-acylethanolamines are vanilloid receptor (TRPV1) agonists. J Biol Chem 2005; 280: 38496-38504.

36 De Petrocellis L, Starowicz K, Moriello AS, et al. Regulation of transient receptor potential channels of melastatin type 8 (TRPM8): effect of cAMP, cannabinoid $\mathrm{CB}_{1}$ receptors and endovanilloids. Exp Cell Res 2007; 313: 1911-1920.

37 Yang YY, Lin HC, Huang YT, et al. Role of $\mathrm{Ca}^{2+}$-dependent potassium channels in in vitro anandamide-mediated mesenteric vasorelaxation in rats with biliary cirrhosis. Liver Int 2007; 27: 1045-1055.

38 Li GL, Winter H, Arends R, et al. Assessment of the pharmacology and tolerability of PF-04457845, an irreversible inhibitor of fatty acid amide hydrolase-1, in healthy subjects. Br J Clin Pharmacol 2012; 73: 706-716.

39 Khalid S, Murdoch R, Newlands A, et al. Transient receptor potential vanilloid 1 (TRPV1) antagonism in patients with refractory chronic cough: a double-blind randomized controlled trial. J Allergy Clin Immunol 2014; 134: 56-62.

40 Belvisi MG, Birrell MA, Wortley MA, et al. Improved pharmacodynamic profile of XEN-D0501, a novel TRPV1 antagonist, over SB705498 does not result in a reduction in cough frequency in patients with chronic idiopathic cough. Am J Respir Crit Care Med 2017; 195: A4499.

41 Smith JA, Birrell MA, Wortley MA, et al. TRPV1 antagonism with XEN-D0501 in chronic obstructive pulmonary disease: translation from pre-clinical model to clinical trial. Am J Respir Crit Care Med 2017; 195: A6339.

42 Abdulqawi R, Dockry R, Holt K, et al. P2X3 receptor antagonist (AF-219) in refractory chronic cough: a randomised, double-blind, placebo-controlled phase 2 study. Lancet 2015; 385: 1198-1205. 